\section{(2) OPEN ACCESS}

\title{
Ambient air pollution exposure and chronic bronchitis in the Lifelines cohort
}

\author{
Dany Doiron, ${ }^{1}$ Jean Bourbeau (1) ,' Kees de Hoogh, ${ }^{2,3}$ Anna L Hansell (i) 4,5
}

\begin{abstract}
- Additional material is published online only. To view please visit the journal online (http://dx.doi.org/10.1136/ thoraxjnl-2020-216142).

${ }^{1}$ Respiratory Epidemiology and Clinical Research Unit, Research Institute of the McGill University, Centre for Outcomes Research and Evaluation, Research Institute of the McGill University Health Centre, Montréal, Québec, Canada ${ }^{2}$ Swiss Tropical and Public Health Institute, Basel, BaselStadt, Switzerland

${ }^{3}$ University of Basel, Basel, Basel-Stadt, Switzerland

${ }^{4}$ Centre for Environmental Health and Sustainability, University of Leicester, Leicester, UK

${ }^{5} \mathrm{MRC}$ Centre for Environment and Health, Department of Epidemiology and Biostatistics, School of Public Health, Imperia College London, London, UK
\end{abstract}

\section{Correspondence to} Dr Dany Doiron, Respiratory Epidemiology and Clinical Research Unit, Research Institute of the McGill University, Centre for Outcomes Research and Evaluation, Research Institute of the McGill University Health Centre, Montreal, Canada; dany.doiron@mail.mcgill.ca

Received 2 September 2020 Revised 16 December 2020 Accepted 8 January 2021 Published Online First 28 January 2021

\section{GLinked}

- http://dx.doi.org/10.1136/ thoraxjnl-2021-216883

\section{Check for updates}

(C) Author(s) (or their employer(s)) 2021. Re-use permitted under CC BY. Published by BMJ.

To cite: Doiron $D$,

Bourbeau J, de Hoogh K, et al. Thorax

2021:76:772-779.

\section{ABSTRACT}

Background Few large studies have assessed the relationship of long-term ambient air pollution exposure with the prevalence and incidence of symptoms of chronic bronchitis and cough.

Methods We leveraged Lifelines cohort data on 132595 (baseline) and 65009 (second assessment) participants linked to ambient air pollution estimates. Logistic regression models adjusted for sex, age, educational attainment, body mass index, smoking status, pack-years smoking and environmental tobacco smoke at home were used to assess associations of air pollution with prevalence and incidence of chronic bronchitis (winter cough and sputum almost daily for $\geq 3$ months/year), chronic cough (winter cough almost daily for $\geq 3$ months/year) and prevalence of cough and sputum symptoms, irrespective of duration.

Results Associations were seen for all pollutants for prevalent cough or sputum symptoms. However, for prevalent and incident chronic bronchitis, statistically significant associations were seen for nitrogen dioxide $\left(\mathrm{NO}_{2}\right)$ and black carbon $(\mathrm{BC})$ but not for fine particulate matter $\left(\mathrm{PM}_{2.5}\right)$. For prevalent chronic bronchitis, associations with $\mathrm{NO}_{2}$ showed OR: $1.05(95 \% \mathrm{Cl}: 1.02$ to 1.08 ) and with $\mathrm{BC}^{2} \mathrm{OR}: 1.06$ (95\% Cl: 1.03 to 1.09$)$ expressed per IQR; corresponding results for incident chronic bronchitis were NO OR: 1.07 (95\% Cl: 1.02 to 1.13 ) and BC OR: 1.07 ( $95 \% \mathrm{Cl}: 1.02$ to 1.13 ). In subgroup analyses, slightly stronger associations were observed among women, never smokers and younger individuals.

Conclusion This is the largest analysis to date to examine cross-sectional and longitudinal associations between ambient air pollution and chronic bronchitis. $\mathrm{NO}_{2}$ and $\mathrm{BC}$ air pollution was associated with increased odds of prevalent and incident chronic bronchitis.

\section{BACKGROUND}

Chronic bronchitis (CB) is characterised by persistent cough and sputum production and is a common phenotype of chronic obstructive pulmonary disease (COPD). Reported prevalence of $\mathrm{CB}$ ranges from $3.4 \%$ to $22 \%$ in the adult population, and from $14 \%$ to $74 \%$ among COPD patients. ${ }^{1}$ In the presence of chronic airflow obstruction, $\mathrm{CB}$ has been related to excess decline in lung function ${ }^{23}$ and to a greater prevalence of other respiratory symptoms and exacerbations. ${ }^{24-8}$ Although there is still debate on the relevance of $\mathrm{CB}$ in individuals with normal spirometry, recent studies have suggested it to be of worse prognosis. In individuals with normal lung function, CB can carry a risk of excess

\section{Key messages}

What is the key question?

$\Rightarrow$ Is long-term ambient air pollution exposure associated with prevalence and incidence of chronic bronchitis and/or cough or sputum symptoms?

What is the bottom line?

$\Rightarrow$ Nitrogen dioxide and black carbon air pollutant concentrations in the northern Netherlands were clearly associated with increased odds of prevalent and incident chronic bronchitis, with higher effect sizes seen among women, never smokers and younger individuals.

Why read on?

$\Rightarrow$ This is the largest study so far on the relationship between ambient air pollution exposure and chronic bronchitis or related symptoms; even at relatively low concentrations compared with urban locations within Europe and internationally, statistically significant associations of long-term air pollution exposure on prevalent and incident chronic bronchitis were observed.

lung function decline and COPD development. ${ }^{9-11}$ Chronic cough and sputum symptoms have been demonstrated to be associated with worse healthrelated quality of life not only in adults with COPD but also in those without airflow obstruction, ${ }^{47812}$ and a recent population-based study showed that CB symptoms have a larger burden on quality of life than chronic airflow obstruction or asthma. ${ }^{8}$ CB symptoms may not be as benign as previously thought when also considering their association with a higher risk of respiratory-related mortality. ${ }^{2}$

The role of outdoor air pollution in respiratory mortality, COPD and asthma has been studied widely, ${ }^{13-16}$ but its role in the prevalence and incidence of $\mathrm{CB}$ needs to be elucidated. Ambient air pollution has been shown to increase hospital admissions for respiratory disease ${ }^{17} 18$ and has been associated with chronic respiratory outcomes such as the development of asthma ${ }^{19}$ and reduced lung function growth in children, ${ }^{20}$ as well as lung function decline and increased COPD prevalence and incidence in adults. ${ }^{21} 22$ In 2015, ambient fine particulate matter and ozone air pollution caused an estimated 1.1 million deaths from COPD worldwide. ${ }^{23}$ In the Western world, smoking is still in itself the most important indicator of risk of $\mathrm{CB}$, but 
other exposures including ambient air pollution must be investigated. Few recent studies have examined the long-term effects of outdoor air pollution exposure on $\mathrm{CB}$ prevalence and incidence. The largest to date, involving 47357 US women followed between 2003 and 2014, found statistically significant associations between particulate matter exposure and prevalence, but not incidence, of CB. ${ }^{24}$ In a 2014 study of five heterogeneous European cohorts ( $\sim 10000)$, no associations were found for $\mathrm{CB}$, but small increases in prevalence of sputum symptoms were reported among never smokers ${ }^{25}$-it did not assess incidence. The objective of this study was to assess the relationship of longterm ambient air pollution exposure with the prevalence and incidence of $\mathrm{CB}$ as well as cough or sputum symptoms in a large population-based study in the Netherlands with linked air pollution estimates.

\section{MATERIALS AND METHODS Study population}

We analysed baseline (2006-2013) and second assessment (2014-2017) data from adults aged 18 to 93 years from the three northernmost, largely rural, provinces of Netherlands (Friesland, Groningen and Drenthe) enrolled in the Lifelines cohort study. General practitioners invited all their patients aged 25-50 years unless they met one or more exclusion criteria: severe psychiatric/physical illness, limited life expectancy $(<5$ years $)$ or insufficient knowledge of the Dutch language to complete a study questionnaire. Recruited individuals were asked to invite family members to participate in the study. Inhabitants of the Friesland, Groningen and Drenthe provinces could also register themselves via the Lifelines website. ${ }^{26}$ Details on Lifelines population sampling and data collection methodology have been outlined elsewhere. ${ }^{26}{ }^{27}$ Participants provided informed consent at recruitment for broad use of their data by local and international investigators. All necessary approvals were obtained from the Lifelines ethics and scientific review boards for this project.

\section{Outcome assessment}

The gold standard definition of $\mathrm{CB}$, as established by the British Medical Research Council (MRC) in 1965, is cough and sputum production for 3 months of the year for at least two consecutive years. ${ }^{28} \mathrm{CB}$ assessment items included in the Lifelines respiratory health questionnaire deviated slightly from this classical definition in that it: (a) specified 'winter' as the time period for recall of respiratory symptoms at baseline and, (b) did not allow assessment of whether symptoms had been present for $\geq 2$ consecutive years. For our study, prevalent (baseline) CB cases were therefore defined as individuals who reported 'coughing up phlegm when getting up, during the daytime, or at night in the winter almost daily for at least 3 months a year'. Incident $\mathrm{CB}$ was defined as individuals 'coughing up mucus every day for a period of 3 months a year', among those not reporting daily cough or daily cough with phlegm $\geq 3$ months a year at baseline (table 1). As evidence suggests that chronic cough and chronic sputum production may represent different pathophysiological processes, ${ }^{3}{ }^{29}$ we considered 'cough without phlegm production almost daily for at least 3 months a year' as a separate outcome at baseline and second assessment. To assess the effect of air pollution exposure with cough and phlegm symptoms, we also considered 'usual cough' and 'usual sputum' during the winter, but not specified as occurring 3 months a year, as prevalent outcomes in separate analyses (table 1). Lifelines CB questionnaire assessment items and recoding procedures used to define outcomes are included as online supplemental table S1.
Table 1 Chronic bronchitis and bronchitis-like symptom definitions

Baseline (2006-2013)

\begin{tabular}{|c|c|}
\hline Prevalent outcomes & Assessment item \\
\hline Chronic bronchitis & $\begin{array}{l}\text { Cough up phlegm in winter when getting up, during } \\
\text { daytime or at night almost daily for at least } 3 \text { months } \\
\text { a year }\end{array}$ \\
\hline Usual sputum & $\begin{array}{l}\text { Usually cough up phlegm in winter when getting up, } \\
\text { during daytime or at night }\end{array}$ \\
\hline Chronic cough & $\begin{array}{l}\text { Cough in winter when getting up, during daytime or } \\
\text { at night almost daily for at least } 3 \text { months a year }\end{array}$ \\
\hline Usual cough & $\begin{array}{l}\text { Usually cough in winter when getting up, during } \\
\text { daytime or at night }\end{array}$ \\
\hline \multicolumn{2}{|c|}{ Follow up (2014-2017) } \\
\hline Incident outcomes & Assessment item \\
\hline Chronic bronchitis & $\begin{array}{l}\text { Cough up mucus every day for a period of } 3 \text { months } \\
\text { a year }\end{array}$ \\
\hline Chronic cough & $\begin{array}{l}\text { Cough almost every day for a period of } 3 \text { months a } \\
\text { year }\end{array}$ \\
\hline
\end{tabular}

\section{Air pollution exposure}

We used annual mean concentrations of particulate matter with a diameter of less than $2.5 \mu \mathrm{m}\left(\mathrm{PM}_{2.5}\right)$, nitrogen dioxide $\left(\mathrm{NO}_{2}\right)$ and black carbon $(\mathrm{BC})$ developed in the context of the Effects of Low-Level Air Pollution: A Study in Europe (ELAPSE) project. ${ }^{3031}$ Land use regression models in ELAPSE were based on 2010 monitoring data from the AirBase dataset for $\mathrm{PM}_{25}$ and $\mathrm{NO}_{2}$ and from the European Study of Cohorts for Air Pollution Effects (ESCAPE) project for BC. Predictor variables in the ELAPSE $\mathrm{PM}_{2,5}$ model included satellite-derived $\mathrm{PM}_{2.5}$ data, long range chemical transport model data for $\mathrm{PM}_{2.5}$, altitude, sum of all roads length, natural land areas, ports and residential areas. $\mathrm{NO}_{2}$ predictors included $\mathrm{NO}_{2}$ chemical transport model data, sum of all roads and major roads lengths, natural land area, ports and residential areas. Because $\mathrm{BC}$ is a major component of $\mathrm{PM}_{2.5}, \mathrm{PM}_{2.5}$ satellite and chemical transport model data were included in the BC models in addition to major roads, all roads, residential areas, urban green spaces and east-west trend. Across western Europe, final models explained $72 \%, 59 \%$ and $54 \%$ of the spatial variation in measured $\mathrm{PM}_{25}, \mathrm{NO}_{2}$ and $\mathrm{BC}$ concentrations, respectively. ${ }^{30}$ When compared with ESCAPE project measured $\mathrm{PM}_{2.5}$ and $\mathrm{NO}_{2}$ concentrations for the Netherlands, the ELAPSE models performed very well for $\mathrm{NO}_{2}\left(\mathrm{R}^{2}=75.9\right)$ but less so for $\mathrm{PM}_{2.5}\left(\mathrm{R}^{2}=12.6\right){ }^{30}$ Residential addresses of Lifelines participants at recruitment were geocoded, which allowed linkage of ELAPSE air pollution estimates.

\section{Statistical analyses}

We conducted descriptive statistics for sociodemographic factors, health outcomes and air pollution. Multivariable logistic regression models were used to explore associations of exposure to $\mathrm{PM}_{2.5}, \mathrm{NO}_{2}$ and $\mathrm{BC}$ with prevalent $\mathrm{CB}$ at baseline. Logistic regression models were also used to estimate associations between air pollution exposure and incident $\mathrm{CB}$ at second assessment. Sociodemographic and behavioural risk factors to include as potential confounders were selected a priori through literature search. Prevalent CB analyses were adjusted for sex, age (continuous), educational attainment (low: junior secondary/lower vocational or less, medium: senior secondary/ secondary vocational, high: higher vocational/university), body mass index (continuous), smoking status (never, past, current), pack-years smoking and exposure to environmental 


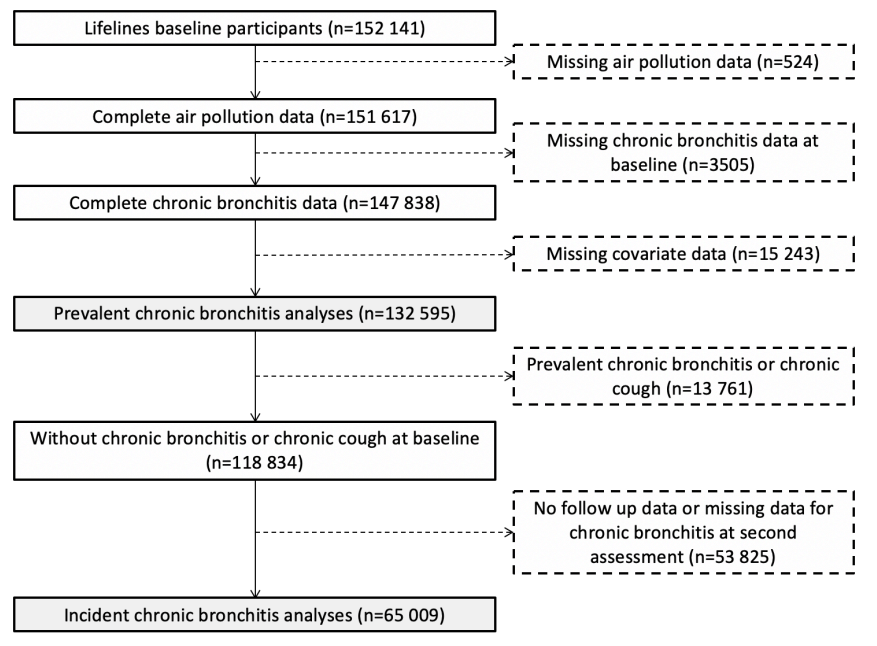

Figure 1 Lifelines study population, missing data and exclusions.

tobacco smoke at home (yes/no). We also explored prevalent (baseline) and incident (second assessment) chronic cough, as well as prevalent usual cough and usual sputum reported at baseline, using logistics regression models adjusted for the same covariates as CB models. Incident analyses were additionally adjusted for follow-up time (continuous) due to potential bias by length of follow-up. In order to explore the temporal stability of $\mathrm{CB}$, we examined the proportion of individuals with persistent $\mathrm{CB}$ - that is, present at baseline and at second assessment-and that of individuals with 'resolved' $\mathrm{CB}$ - that is, present at baseline but not at second assessment.

Sensitivity analyses were conducted for the following subgroups: women, individuals aged 50 years and older, individuals without post-secondary education, never smokers and asthmatics. For both prevalent and incident outcomes, we conducted two-pollutant models which included $\mathrm{NO}_{2}$ and $\mathrm{PM}_{2.5}$ in order to differentiate the roles of co-occurring air pollutants on respiratory outcomes. To assess the impact of a change of residence and potential for exposure misclassification on incident $\mathrm{CB}$ results, we excluded individuals who reported moving houses between baseline and follow-up assessments in sensitivity analyses. Finally, all analyses were conducted on participants with complete data for respiratory outcomes, air pollution exposure and confounders. Statistical analyses were conducted using the $\mathrm{R}$ statistical package, V.3.5.2 (20 December 2018). ${ }^{32}$

\section{RESULTS}

\section{Study population}

Figure 1 shows Lifelines study population, exclusions and missing data. Of the 152141 participants recruited at baseline, 4029 had missing data for either air pollution or CB and 15243 had missing data for covariates, resulting in a sample of 132595 individuals for prevalent CB analyses, that is, the 'prevalent cohort'. After excluding 13761 individuals reporting either $\mathrm{CB}$ or daily cough at least 3 months a year at baseline, and 53825 with either no follow-up data or missing data for $\mathrm{CB}$ at second asessement, 65009 participants were included in incident CB analyses, that is, the 'incident cohort'. Descriptive analyses (table 2) showed that participants on average were in their mid-40s, three out of five were women and one-third had higher education. About half of individuals were never smokers, while one-third and one-fifth were
Table 2 Lifelines study population characteristics

\begin{tabular}{|c|c|c|}
\hline & $\begin{array}{l}\text { Baseline assessment* } \\
(\mathrm{n}=132595)\end{array}$ & $\begin{array}{l}\text { Second } \\
\text { assessment }{ }^{*} \\
(\mathrm{n}=65009)\end{array}$ \\
\hline \multicolumn{3}{|l|}{ Sex } \\
\hline Male, n (\%) & $55315(41.7)$ & $26325(40.5)$ \\
\hline Female, n (\%) & $77280(58.3)$ & $38684(59.5)$ \\
\hline Age, mean $\pm S D$ & $44.1 \pm 12.6$ & $45.8 \pm 12.2$ \\
\hline \multicolumn{3}{|l|}{ Educationt } \\
\hline Low, n (\%) & $38229(28.8)$ & $18796(28.9)$ \\
\hline Medium, n (\%) & $53433(40.3)$ & $25826(39.7)$ \\
\hline High, n (\%) & $40933(30.9)$ & $20387(31.4)$ \\
\hline \multicolumn{3}{|l|}{ Smoking status } \\
\hline Total never smoker, n (\%) & $62895(47.4)$ & $31542(48.5)$ \\
\hline Total former smoker, n (\%) & $43079(32.5)$ & $23149(35.6)$ \\
\hline Total current smoker, n (\%) & $26621(20.1)$ & $10318(15.9)$ \\
\hline Male never smoker, $\mathrm{n}(\%)$ & $24765(44.8)$ & $12175(46.2)$ \\
\hline Male former smoker, n (\%) & $18414(33.3)$ & $9700(36.8)$ \\
\hline Male current smoker, n (\%) & $12136(21.9)$ & 4450 (16.9) \\
\hline Female never smoker, n (\%) & $38130(49.3)$ & $19367(50.1)$ \\
\hline Female former smoker, $\mathrm{n}(\%)$ & $24665(31.9)$ & $13449(34.8)$ \\
\hline Female current smoker, n (\%) & $14485(18.7)$ & $5868(15.2)$ \\
\hline Pack-years smoking, mean $\pm \mathrm{SD} \ddagger$ & $11.8 \pm 10.9$ & $11.2 \pm 10.4$ \\
\hline \multicolumn{3}{|l|}{ Asthma } \\
\hline Never diagnosed with asthma & $120783(91.2)$ & 60468 (93.1) \\
\hline Ever diagnosed with asthma & $11612(8.8)$ & $4453(6.9)$ \\
\hline Chronic bronchitis, n (\%) & $8128(6.1)$ & $2946(4.5)$ \\
\hline Usual sputum & $13687(10.3)$ & - \\
\hline $\begin{array}{l}\text { Chronic cough (daily cough, } 3 \text { months } \\
\text { a year), } n(\%)\end{array}$ & $9754(7.4)$ & $3956(6.1)$ \\
\hline Usual cough & $19564(14.8)$ & - \\
\hline \multicolumn{3}{|c|}{$\begin{array}{l}\text { *For participants with complete data for chronic bronchitis, sex, age, educational } \\
\text { attainment, BMI, smoking status, pack-years smoking, environmental tobacco } \\
\text { smoke at home and nitrogen dioxide. } \\
\text { †Educational attainment levels: low=junior secondary/lower vocational or less; } \\
\text { medium=senior secondary/secondary vocational; high=higher vocational/university } \\
\text { łPack-years smoking are for current and former smokers (baseline: } n=69700 \text {; } \\
\text { second assessment: } n=33 \text { 467). } \\
\text { BMI, body mass index. }\end{array}$} \\
\hline
\end{tabular}

former and current smokers, respectively. The proportion of never smokers at baseline was slightly higher for women $(49.3 \%)$ relative to men $(44.8 \%)$. CB prevalence was $6.1 \%$ at baseline while $\mathrm{CB}$ incidence was $4.5 \%$ at second assessment. Chronic cough prevalence and incidence were $7.4 \%$ and $6.1 \%$, respectively. Mean follow-up between baseline and second assessment was 46.5 months ( $S D=14.02$ months), with a range of 13-122 months. Significant differences were found for all variables between the baseline population used in our analyses $(n=132$ 595) and individuals with missing data for respiratory outcomes, air pollution exposure or confounders $(n=19546)$ (online supplemental table S2). Mean \pm SD average ambient concentrations of $\mathrm{PM}_{2.5}, \mathrm{NO}_{2}$ and $\mathrm{BC}$ at baseline residential locations of Lifelines participants were $14.8 \pm 1.02 \mu \mathrm{g} /$ $\mathrm{m}^{3}, 21.5 \pm 4.99 \mu \mathrm{g} / \mathrm{m}^{3}$ and $1.22 \pm 0.2310^{-5} \mathrm{~m}^{-1}$, respectively. $\mathrm{PM}_{2.5}$ was moderately correlated with $\mathrm{NO}_{2}(\mathrm{r}=0.57)$ and $\mathrm{BC}$ 
Table 3 Baseline air pollution concentrations descriptive statistics

\begin{tabular}{llllllllll}
\hline & & & & & & & \multicolumn{2}{c}{ Pearson correlation coefficients (95\% Cl) } \\
\cline { 8 - 10 } & Mean (SD) & Min & Max & IQR & $\mathbf{n}$ & $\mathbf{P M}_{2.5}$ & $\mathrm{NO}_{2}$ & Black carbon \\
\hline $\mathrm{PM}_{2.5}\left(\mu \mathrm{g} / \mathrm{m}^{3}\right)$ & $14.8(1.02)$ & 9.35 & 21.8 & 1.30 & 135226 & 1.000 & $0.565(0.561$ to 0.568$)$ & $0.480(0.476$ to 0.484$)$ \\
\hline $\mathrm{NO}_{2}\left(\mu \mathrm{g} / \mathrm{m}^{3}\right)$ & $21.5(4.99)$ & 9.07 & 65.4 & 6.92 & 135226 & & 1.000 & $0.889(0.888$ to 0.890$)$ \\
\hline Black carbon $\left(10^{-5} \mathrm{~m}^{-1}\right)$ & $1.22(0.23)$ & 0.65 & 3.15 & 0.29 & 135226 & & & 1.000
\end{tabular}

For participants with complete data for chronic bronchitis, sex, age, educational attainment, BMI, smoking status, pack-years smoking, environmental tobacco smoke at home.

$\mathrm{BMI}$, body mass index; $\mathrm{NO}_{2}$, nitrogen dioxide; $\mathrm{PM}_{2.5}$, particulate matter with a diameter of less than $2.5 \mu \mathrm{m}$.

$(\mathrm{r}=0.48)$, while a high correlation was seen between $\mathrm{NO}_{2}$ and BC (0.89) (table 3).

\section{Prevalence of $C B$ and respiratory symptoms}

Logistic regression results for prevalent outcomes are presented in table 4. Higher odds of $\mathrm{CB}$ were seen for exposure to $\mathrm{NO}_{2}$ and $\mathrm{BC}$ air pollution but not for $\mathrm{PM}_{2.5}$, after adjusting for confounding factors. Statistically significant positive associations were also seen for prevalent chronic cough and exposure to ambient BC, as well as for odds of usual cough and usual sputum and exposure to each ambient $\mathrm{BC}, \mathrm{NO}_{2}$ and $\mathrm{PM}_{25}$.

In subgroup analyses (table 5), women and never smokers showed similar patterns of associations with slightly higher effect sizes compared with full analyses. Among never smokers, higher odds of $\mathrm{CB}$ were seen for $\mathrm{NO}_{2}$ and marginally higher for $\mathrm{BC}$ exposure. Associations between each pollutant and prevalent usual cough and usual sputum were also stronger among asthmatics. Restricting association to individuals with no post-secondary education yielded similar associations for each pollutant and each outcome as seen in the overall population. Finally, individuals aged 50 years and older generally showed reduced effect sizes compared with overall population. No associations were found between any air pollutants and prevalent respiratory outcomes in this subgroup except for the following: prevalent usual cough was associated with exposure to $\mathrm{NO}_{2}$ and $\mathrm{BC}$ and chronic cough was associated with BC.

\section{Incidence of $\mathrm{CB}$ and respiratory symptoms}

Table 6 shows results of incident $\mathrm{CB}$ and chronic cough at second assessment. Consistent with results for $\mathrm{CB}$ prevalence, statistically significant positive associations were seen between incident $\mathrm{CB}$ and exposure to ambient $\mathrm{NO}_{2}$ and $\mathrm{BC}$, but not for $\mathrm{PM}_{2.5}$. Incident chronic cough was not associated with air pollution exposure. Per IQR increase in $\mathrm{NO}_{2}$ and $\mathrm{BC}$, ORs for incident $\mathrm{CB}$ were higher among women and never smokers relative to full analyses. When limiting analyses to never smokers, associations between $\mathrm{NO}_{2}$ and $\mathrm{BC}$ exposure and incident chronic cough became larger and statistically significant. Approximately the same proportion of individuals reported persistent CB (ie, present at baseline and second assessment; 1.4\%) as did individuals reporting 'resolved' CB (ie, present at baseline but not at second assessment; 1.6\%) (online supplemental table S3).

\section{Sensitivity analyses}

Of the 65009 participants with complete data for incident analyses, 9130 individuals (14.1\%) reported moving residences between baseline and follow-up assessments. When limiting incident $C B$ analyses to non-movers $(n=55602)$, positive, though not statistically significant, associations were found for $\mathrm{NO}_{2}$ air pollution while associations for $\mathrm{BC}$ remained statistically significant (online supplemental table S4). In two-pollutant models, associations between $\mathrm{PM}_{2.5}$ exposure and prevalent respiratory symptoms were attenuated to the null after adjustment for $\mathrm{NO}_{2}$ exposure (online supplemental table S5). Conversely, associations between $\mathrm{NO}_{2}$ and $\mathrm{CB}$ prevalence and incidence were slightly stronger when adjusting for $\mathrm{PM}_{2.5}$, while $\mathrm{NO}_{2}$ associations with prevalent and incident respiratory symptoms were robust to $\mathrm{PM}_{2.5}$ adjustment.

\section{DISCUSSION}

To our knowledge, this study is the largest to date to explore the associations of long-term exposure to outdoor air pollution with $\mathrm{CB}$. Exposure to ambient $\mathrm{NO}_{2}$ and $\mathrm{BC}$ air pollution, but not $\mathrm{PM}_{2,5}$, were associated with increased odds of both prevalent and incident CB. Prevalent but not incident chronic cough was also associated with $\mathrm{BC}$ air pollution exposure. All three pollutants explored also showed positive associations with prevalence of usual cough and usual sputum. In both prevalence and incidence analyses, we demonstrated slightly stronger associations of respiratory outcomes with exposure to $\mathrm{NO}_{2}$ and $\mathrm{BC}$ air pollution among women, never smokers and younger individuals. Stronger associations were also seen in asthmatics for exposure to air pollution and prevalent cough and sputum symptoms.

Table 4 Prevalent chronic bronchitis and cough and sputum symptoms at baseline per IQR increase in each pollutant

\begin{tabular}{|c|c|c|c|c|}
\hline \multirow[b]{2}{*}{ All participants } & \multirow[b]{2}{*}{ Cases/non-cases (n/n) } & \multicolumn{3}{|c|}{ Adjusted* OR (95\% Cl) } \\
\hline & & $\mathrm{PM}_{2.5}$ & $\mathrm{NO}_{2}$ & Black carbon \\
\hline Chronic bronchitis & $8128 / 124467$ & 1.01 (0.98 to 1.04 ) & 1.05 (1.02 to 1.08$)$ & 1.06 (1.03 to 1.09$)$ \\
\hline Chronic cough & 9754/122 915 & 1.00 (0.97 to 1.03$)$ & 1.03 (1.00 to 1.06$)$ & 1.05 (1.02 to 1.08$)$ \\
\hline Usual cough & $19564 / 112409$ & 1.03 (1.01 to 1.05$)$ & 1.07 (1.05 to 1.09$)$ & 1.07 (1.05 to 1.09$)$ \\
\hline
\end{tabular}


Table 5 Subgroup analyses for prevalent chronic bronchitis and cough and sputum symptoms at baseline, per IQR increase in each pollutant

\begin{tabular}{|c|c|c|c|c|}
\hline & \multirow[b]{2}{*}{ Cases/non-cases $(\mathbf{n} / \mathbf{n})$} & \multicolumn{3}{|c|}{ Adjusted* OR (95\% Cl) } \\
\hline & & $\mathrm{PM}_{2.5}$ & $\mathrm{NO}_{2}$ & Black carbon \\
\hline \multicolumn{5}{|l|}{ Females } \\
\hline Chronic bronchitis & 4070/73 210 & 1.03 (0.99 to 1.08$)$ & 1.08 (1.03 to 1.13$)$ & 1.08 (1.04 to 1.13$)$ \\
\hline Usual sputum & 7268/69 987 & 1.05 (1.02 to 1.08$)$ & 1.08 (1.04 to 1.12$)$ & $1.08(1.05$ to 1.11$)$ \\
\hline Chronic cough & $5384 / 71924$ & 1.03 (0.99 to 1.07$)$ & 1.07 (1.03 to 1.11$)$ & $1.08(1.04$ to 1.11$)$ \\
\hline Usual cough & 11 194/65 731 & 1.04 (1.02 to 1.07$)$ & 1.09 (1.06 to 1.12$)$ & 1.09 (1.06 to 1.12$)$ \\
\hline \multicolumn{5}{|l|}{ Age $>=50$} \\
\hline Chronic bronchitis & 2669/37 639 & 0.98 (0.94 to 1.03$)$ & 0.99 (0.94 to 1.05$)$ & 1.03 (0.98 to 1.09 ) \\
\hline Usual sputum & $4104 / 36162$ & 1.01 (0.98 to 1.06$)$ & 1.01 (0.97 to 1.06$)$ & 1.03 (0.99 to 1.08$)$ \\
\hline Chronic cough & 2999/37 333 & 0.99 (0.94 to 1.03$)$ & 1.02 (0.97 to 1.08$)$ & $1.06(1.01$ to 1.11$)$ \\
\hline Usual cough & $5457 / 36606$ & 1.01 (0.97 to 1.04$)$ & 1.05 (1.01 to 1.09$)$ & $1.06(1.02$ to 1.10$)$ \\
\hline \multicolumn{5}{|c|}{ No post-secondary education } \\
\hline Chronic bronchitis & $6120 / 85542$ & $1.00(0.96$ to 1.03$)$ & $1.06(1.02$ to 1.10$)$ & $1.07(1.03$ to 1.11$)$ \\
\hline Usual sputum & $10293 / 81340$ & 1.02 (0.99 to 1.05$)$ & $1.07(1.04$ to 1.10$)$ & $1.08(1.05$ to 1.11$)$ \\
\hline Chronic cough & 7427/84 296 & $1.00(0.97$ to 1.03$)$ & 1.04 (1.00 to 1.08$)$ & $1.06(1.03$ to 1.10$)$ \\
\hline Usual cough & $14625 / 76626$ & 1.03 (1.01 to 1.06$)$ & $1.08(1.05$ to 1.11$)$ & $1.08(1.06$ to 1.11$)$ \\
\hline \multicolumn{5}{|l|}{ Never smokers } \\
\hline Chronic bronchitis & 2960/59 935 & 1.03 (0.98 to 1.08$)$ & 1.09 (1.03 to 1.14$)$ & 1.07 (1.02 to 1.12$)$ \\
\hline Usual sputum & $5426 / 57441$ & $1.05(1.02$ to 1.09$)$ & 1.10 (1.06 to 1.14$)$ & 1.08 (1.05 to 1.12$)$ \\
\hline Chronic cough & $3472 / 59456$ & $1.04(1.00$ to 1.09$)$ & 1.05 (1.01 to 1.11$)$ & $1.06(1.02$ to 1.11$)$ \\
\hline Usual cough & $8115 / 54585$ & $1.07(1.04$ to 1.10$)$ & 1.09 (1.06 to 1.13$)$ & $1.08(1.05$ to 1.11$)$ \\
\hline \multicolumn{5}{|l|}{ Asthmatics } \\
\hline Chronic bronchitis & $1781 / 9831$ & $0.99(0.92$ to 1.05$)$ & $1.03(0.96$ to 1.11$)$ & 1.04 (0.97 to 1.11 ) \\
\hline Usual sputum & $2820 / 8802$ & $1.10(1.04$ to 1.16$)$ & 1.12 (1.06 to 1.19$)$ & $1.12(1.07$ to 1.19$)$ \\
\hline Chronic cough & 2039/9589 & $1.04(0.97$ to 1.10$)$ & 1.05 (0.98 to 1.12$)$ & 1.07 (1.01 to 1.14 ) \\
\hline Usual cough & $3362 / 8209$ & $1.06(1.00$ to 1.11$)$ & 1.08 (1.02 to 1.14$)$ & 1.10 (1.04 to 1.15$)$ \\
\hline
\end{tabular}

Statistically significant results are shown in bold.

* Model adjusted for sex, age, educational attainment (low: junior secondary/lower vocational or less, medium: senior secondary/secondary vocational, high: higher vocational/ university), BMI (continuous), smoking status (never, ex, current), pack-years smoking and environmental tobacco smoke at home. IQR for $\mathrm{PM} \mathrm{L}_{2.5}=1.30 \mu \mathrm{g} / \mathrm{m}^{3}$, for $\mathrm{NO}{ }_{2}=6.92 \mu \mathrm{gg} / \mathrm{m}^{3}$ and for $\mathrm{BC}=0.29 \times 10^{-5} \mathrm{~m}^{-1}$.

$\mathrm{BC}$, black carbon; $\mathrm{BMI}$, body mass index; $\mathrm{NO}_{2}$, nitrogen dioxide; $\mathrm{PM}_{2.5}$, particulate matter with a diameter of less than $2.5 \mu \mathrm{m}$.

Although comparisons with previous studies are limited given different definitions and questionnaires used for CB and symptoms assessment, as well as variations in air pollution exposure estimation methods, evidence reported in past literature are in line with associations seen in the current study. Our results confirm stronger associations previously reported among never smokers. A large study involving 47357 US women followed from 2003 to 2014, found significant associations between particulate matter with a diameter $<10 \mu \mathrm{m}\left(\mathrm{PM}_{10}\right)$ and prevalence (OR: $1.07,95 \%$ CI: 1.01 to 1.13 , per $5.8 \mu \mathrm{g} / \mathrm{m}^{3}$ increase), but not incidence, of $\mathrm{CB} .{ }^{24}$ When limiting analyses to never smokers, this study showed that prevalent (ie, baseline) CB was also associated with exposure to $\mathrm{PM}_{25}$ (OR: $1.18,95 \%$ CI: 1.04 to 1.34 , per $4.4 \mu \mathrm{g} / \mathrm{m}^{3}$ increase) and $\mathrm{NO}_{2}$ (OR: $1.10,95 \% \mathrm{CI}$ : 1.01 to 1.20 , per $7.3 \mathrm{ppb}$ increase). While no associations were found between CB and ambient air pollution in a 2014 crosssectional analysis of five European cohorts $(n>10000)$ in the ESCAPE project, increases in sputum symptoms were reported among never smokers for $\mathrm{PM}_{10}$ (OR: 1.32, 95\% CI: 1.02 to 1.71 , per $10 \mu \mathrm{g} / \mathrm{m}^{3}$ increase) and particulate matter with a diam-

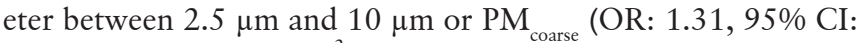
1.05 to 1.64 , per $5 \mu \mathrm{g} / \mathrm{m}^{3}$ increase). A study of 9651 individuals enrolled in the Swiss Study on Air Pollution and Lung Disease in Adults (SAPALDIA) found positive associations between a $10 \mu \mathrm{g} / \mathrm{m}^{3}$ increase in annual mean concentrations of $\mathrm{PM}_{10}$ and reported prevalence of chronic sputum (OR: 1.35, 95\% CI: 1.11 to 1.65 ) and chronic cough or sputum (OR: $1.27,95 \%$ CI: 1.08 to 1.50 ) among never smokers, but not among current or former smokers. ${ }^{33}$ Stronger associations between air pollution and other respiratory outcomes such as COPD and lung function among never smokers have also been reported. ${ }^{22} 34$ Smoking could saturate the effects of other exposures on respiratory outcomes; additional impacts of air pollution might therefore be smaller and more difficult to detect among past and current tobacco smokers.

As in our study, higher susceptibility of women to the impacts of ambient air pollution exposure on bronchitis symptoms has been reported. In a European Community Respiratory Health Survey analysis involving 6924 subjects in 10 European countries, associations between chronic sputum and ambient $\mathrm{NO}_{2}$ concentrations were seen in women (OR: 1.76, 95\% CI: 1.04 to 2.98 , per $30 \mu \mathrm{g} / \mathrm{m}^{3}$ increase), but not in men. ${ }^{35}$ In line with air pollution research, evidence shows that compared with men with similar levels of chronic airflow obstruction, women may be more susceptible to smoking effects on lung function and respiratory symptoms than men. ${ }^{36}$ Biological factors such as 
Table 6 Incident chronic bronchitis and chronic cough at second assessment, per IQR increase in each pollutant

\begin{tabular}{|c|c|c|c|c|}
\hline \multirow{3}{*}{ All participants } & \multirow[b]{2}{*}{ Cases/non-cases (n/n) } & \multicolumn{3}{|c|}{ Adjusted* OR $(95 \% \mathrm{Cl})$} \\
\hline & & \multirow[t]{2}{*}{$\mathrm{PM}_{2.5}$} & \multirow[t]{2}{*}{$\mathrm{NO}_{2}$} & \multirow[t]{2}{*}{ Black carbon } \\
\hline & & & & \\
\hline Chronic bronchitis & $2946 / 62063$ & 1.01 (0.96 to 1.06$)$ & $1.07(1.02$ to 1.13$)$ & 1.07 (1.02 to 1.13$)$ \\
\hline Chronic cough & $3956 / 61022$ & 1.01 (0.96 to 1.05 ) & 1.03 (0.98 to 1.08$)$ & 1.03 (0.99 to 1.08$)$ \\
\hline \multicolumn{5}{|l|}{ Females } \\
\hline Chronic bronchitis & 1479/37 205 & 1.03 (0.96 to 1.10$)$ & $1.11(1.03$ to 1.20$)$ & 1.10 (1.02 to 1.17$)$ \\
\hline Chronic cough & 2099/36563 & 1.03 (0.97 to 1.09 ) & 1.07 (1.00 to 1.14$)$ & 1.05 (0.99 to 1.12$)$ \\
\hline \multicolumn{5}{|l|}{ Age $>=50$} \\
\hline Chronic bronchitis & $1229 / 21619$ & 0.97 (0.91 to 1.03$)$ & 1.02 (0.95 to 1.10$)$ & 1.05 (0.98 to 1.12$)$ \\
\hline Chronic cough & $1645 / 21186$ & 0.99 (0.93 to 1.04$)$ & 1.02 (0.96 to 1.09 ) & $1.03(0.97$ to 1.09$)$ \\
\hline \multicolumn{5}{|c|}{ No post-secondary education } \\
\hline Chronic bronchitis & 2233/42 389 & 1.01 (0.96 to 1.07 ) & 1.08 (1.01 to 1.15$)$ & 1.08 (1.02 to 1.15$)$ \\
\hline Chronic cough & 2996/41601 & 1.01 (0.97 to 1.06$)$ & 1.04 (0.99 to 1.11$)$ & 1.05 (1.00 to 1.11$)$ \\
\hline \multicolumn{5}{|l|}{ Never smokers } \\
\hline Chronic bronchitis & $1090 / 30452$ & 1.04 (0.96 to 1.12 ) & 1.14 (1.05 to 1.25$)$ & 1.14 (1.06 to 1.23$)$ \\
\hline Chronic cough & $1507 / 30021$ & 1.04 (0.97 to 1.11$)$ & 1.11 (1.03 to 1.19$)$ & 1.08 (1.01 to 1.16$)$ \\
\hline \multicolumn{5}{|l|}{ Asthmatics } \\
\hline Chronic bronchitis & $418 / 4035$ & 1.05 (0.92 to 1.20$)$ & 1.09 (0.94 to 1.27$)$ & 1.11 (0.97 to 1.27 ) \\
\hline Chronic cough & $462 / 3990$ & 0.98 (0.86 to 1.12 ) & $1.08(0.93$ to 1.25$)$ & $1.06(0.93$ to 1.21$)$ \\
\hline
\end{tabular}

Statistically significant results are shown in bold.

*Model adjusted for sex, age, educational attainment (low: junior secondary/lower vocational or less, medium: senior secondary/secondary vocational, high: higher vocational/ university), BMI (continuous), smoking status (never, ex, current), pack-years smoking, environmental tobacco smoke at home and follow-up time.

$\mathrm{BMI}$, body mass index; $\mathrm{NO}_{2}$, nitrogen dioxide; $\mathrm{PM}_{2.5}$, particulate matter with a diameter of less than $2.5 \mu \mathrm{m}$.

differences in airway reactivity and metabolism of inhaled particles between men and women have been proposed for such sex differences. ${ }^{3839}$ A better estimation of air pollution exposure due to more time spent at home could also explain larger associations among women. Although overall indoor air quality was not directly measured, this potential source of bias is largely mitigated by the use of environmental tobacco smoke exposure as an adjustment factor in all regression models.

Evidence for effect modification by age on the relationship between air pollution exposure and CB is limited. In our study, subgroup analyses found few significant associations in individuals 50 years and older. This might partly explain the unexpected null associations found by Cai et $a l^{25}$; three of the five cohorts included in the ESCAPE Study had a mean age $>50$ years at baseline assessment. A longitudinal study of 1421 individuals aged 21-80 at recruitment also found CB to be an independent risk factors for incident COPD and mortality risk among subjects younger than 50 years, but not among subjects 50 years and older. ${ }^{40}$ Additional research exploring age-stratified effects of air pollution exposure on CB is therefore warranted.

The ELAPSE air pollution models used to estimate air pollution exposure in our study were robust explaining 58\% and 66\% of respectively $\mathrm{NO}_{2}$ and $\mathrm{PM}_{2,5}$ concentration in hold-out validation. ${ }^{30}$ When validated against ESCAPE monitoring data, the ELAPSE model explained $76 \%$ of the spatial variability in the measured $\mathrm{NO}_{2}$ at the ESCAPE sites, but only $12.6 \%$ for $\mathrm{PM}_{2.5}$. The low correlation between ELAPSE predicted and ESCAPE measured $\mathrm{PM}_{2.5}$ concentrations could be due to the small variation in $\mathrm{PM}_{2.5}$ concentrations $\left(\mathrm{SD}=1.8 \mu \mathrm{g} / \mathrm{m}^{3}\right)$ in the Netherlands and the small number of $\mathrm{PM}_{2.5}$ ESCAPE sites $(n=34)$ used for validation. Participants' exposure was estimated based on 2010 measurement data although recruitment and follow-up
$\mathrm{CB}$ and respiratory symptom measurements ranged from 2006 to 2017. A study by de Hoogh et $a l^{30}$ investigated the stability of the $2010 \mathrm{NO}_{2}$ Western European LUR model by comparing the $2010 \mathrm{NO}_{2}$ predictions with predictions from $\mathrm{NO}_{2}$ LUR models for 2005 and 2000 at 454 randomly selected points in the Netherlands. ${ }^{30}$ They found a good correlation between the 2010 predictions and the 2005 (88\%) and the 2000 (82\%) $\mathrm{NO}_{2}$ predictions. Eeftens et al developed $\mathrm{NO}_{2}$ LUR models for 2007 and 1999-2000 and applying these to $\mathrm{NO}_{2}$ measurements from respectively 1999-2000 and 2007. ${ }^{41}$ They found that the 2007 and 1999-2000 models were able to explain $77 \%$ and $81 \%$ of the spatial variability in the 1999-2000 and $2007 \mathrm{NO}_{2}$ measurements, respectively. Both these studies give confidence that $\mathrm{NO}_{2}$ models for the Netherlands remain spatially stable over time during the study period.

This study has important public health implications. Annual mean $\mathrm{NO}_{2}$ exposure in our study was $21.5 \mu \mathrm{g} / \mathrm{m}^{3}$, about half the $40 \mu \mathrm{g} / \mathrm{m}^{3}$ threshold established by the WHO to protect public health. Even at relatively low concentrations compared with urban locations within Europe and internationally, statistically significant associations of long-term $\mathrm{NO}_{2}$ air pollution exposure on $\mathrm{CB}$ and cough and sputum symptoms were observed. The stronger associations of $\mathrm{CB}$ prevalence and incidence per IQR increase of $\mathrm{BC}$ compared with $\mathrm{PM}_{25}$ might also indicate that combustion-related particulate substances that dominate $\mathrm{BC}$ are more harmful to lung health compared with overall $\mathrm{PM}_{2.5}$. Fine particulate matter air pollution sources include combustion as well as mechanical (eg, brake and tire wear) traffic emissions, residential biomass burning, suspended dust and industry. BC is an important component of $\mathrm{PM}_{2.5}$ emitted largely from gas and diesel engines and power plants, whereas $\mathrm{NO}_{2}$ comes mainly from traffic-related fossil fuel combustion. While we did not 
have source-specific information for estimated air pollutants, positive associations seen for $\mathrm{NO}_{2}$ and $\mathrm{BC}$ reported in our study suggest that policies targeting reduction of air pollution from combustion emissions, as well as traffic abatement measures might help maximise health benefits. ${ }^{42}$ Positive associations were found for $\mathrm{PM}_{2.5}$ exposure and prevalent usual cough and usual sputum, but not for CB. Non-significant associations for $\mathrm{PM}_{25}$ exposure might in part be explained by the lower performance (ie, lower $\mathrm{R}^{2}$ ) of the ELAPSE $\mathrm{PM}_{2.5}$ model, which could be related to more important exposure misclassification for this pollutant. However, the differences may not all be due to exposure misclassification bias. As noted above, it may be that local traffic-related $\mathrm{PM}$, which $\mathrm{NO}_{2}$ and $\mathrm{BC}$ provide a proxy measure of, are the most important exposure in relation to generation of respiratory symptoms. This hypothesis is supported by results from two-pollutant models in our study; $\mathrm{PM}_{2.5}$ exposure and prevalent respiratory symptoms were attenuated to the null after adjustment for $\mathrm{NO}_{2}$ exposure (online supplemental table S5), suggesting local traffic exposure component of PM (as captured by $\mathrm{NO}_{2}$ ) is an important driver of findings. Previous studies have reported associations between $\mathrm{CB}$ and cough and sputum symptoms with larger fractions of particulate matter $\left(\mathrm{PM}_{10}\right.$ and $\mathrm{PM}_{\text {coarse }}$ ), but not fine particulates. ${ }^{24}{ }^{25}$ However, given coarse particulate matter was not modelled in the ELAPSE project, its impact on respiratory outcomes could not be investigated.

Varying case definitions for CB have been used in epidemiological studies, leading to differences in reported prevalence of the disease. Relative to the classical CB definition established by the MRC, our study used a less stringent definition by not specifying persistence of symptoms for 2 years or more. Prevalent CB in our study was also limited to winter symptoms. In the Latin American Project for Research in Pulmonary Obstruction Study, the prevalence of $\mathrm{CB}$ doubled when comparing the classical definition to a less stringent definition. ${ }^{7}$ Nonetheless, very similar clinical phenotypes have been found between individuals characterised with classically defined $\mathrm{CB}$, compared with individuals reporting $\mathrm{CB}$ with less stringent definitions. For example, Kim and colleagues showed that regardless of the definitions used, individual reporting cough and sputum had a higher level of dyspnoea, more respiratory symptoms and a larger number of total and severe exacerbation-like events. ${ }^{43}$ The use of less stringent $\mathrm{CB}$ definitions is also helpful in detecting chronic respiratory symptoms related to long-term air pollution exposure that would not be identified using the gold standard CB definition.

Most studies exploring associations between $\mathrm{CB}$ and air pollution have been cross-sectional, in part because of lack of longitudinal data but also because of concerns that reporting of $\mathrm{CB}$ may vary over time. We found that a small proportion of individuals (1.6\%) reported CB remittance at follow-up (online supplemental table S3). Part of this variation might be due to slightly different CB assessment items used for baseline and second assessment respiratory questionnaires. Longitudinal studies have shown that individuals with new or persistent $\mathrm{CB}$ symptoms are more likely to have continued smoking during follow-up, while individuals with 'resolved' CB (present at baseline but absent at follow-up) are more likely to have quit smoking. ${ }^{44}$ Given the temporal stability in the spatial patterns of air pollutant concentrations in the Netherlands, ${ }^{41}$ we expect participant-specific air pollution exposure to have been relatively constant between baseline and second assessment and do not expect differential exposure misclassification to be a major problem.

The use of ORs as an estimate of risk ratios (RR) may have overestimated risks of air pollution exposure in relation to respiratory health outcomes and we note that our effect sizes are small. However, ORs are accepted to provide a reasonable approximation of risk when disease prevalence/incidence is rare (ie, $<10 \%)^{45}{ }^{46}$; in our study CB prevalence and incidence were $6.1 \%$ and $4.5 \%$, respectively, and chronic cough prevalence and incidence were $7.4 \%$ and $6.1 \%$, respectively. Further, use of adjusted ORs from logistic regressions allowed direct comparison with the literature on air pollution and prevalent and incident $\mathrm{CB}$ and cough or phlegm symptoms, as most comparable previous studies report ORs. A limitation of the study is the large number of participants ( $\mathrm{n}=19$ 546) with missing data for outcomes, confounders or exposures included in baseline regression models. Missingness did not appear to be at random (online supplemental table S2), which limited our ability to conduct imputation. While missing data does not invalidate findings from our study, it may impact their generalisability. A key strength of our study relative to past investigations was the large sample size, which allowed us to detect relatively small effect sizes and explore associations in potentially vulnerable subgroups. Our results are reinforced by recent cross-sectional analyses of the Lifelines cohort which showed positive associations between ambient air pollution exposure and wheeze and shortness of breath. ${ }^{47}$ Lastly, we used standardised air pollution models from the ELAPSE project, which are now being used in numerous epidemiological studies across Europe studying the association between air pollution and multiple health endpoints. The results of this study will therefore complement these ongoing studies.

In conclusion, this is the largest analysis to date to examine cross-sectional and longitudinal associations between ambient air pollution and $\mathrm{CB}$. Higher $\mathrm{NO}_{2}$ and $\mathrm{BC}$ air pollutant concentrations, largely driven by local traffic-related pollution, were associated with increased odds of prevalent and incident CB. We observed higher effect sizes among women, never smokers and younger individuals. These results are of public health importance considering they are seen at relatively low air pollutant concentrations compared with urban locations within Europe and internationally.

Acknowledgements The authors wish to acknowledge the services of the Lifelines Cohort Study, the contributing research centres delivering data to Lifelines and all the study participants. The Lifelines Cohort Study initiative has been made possible by subsidy from the Dutch Ministry of Health, Welfare and Sport, the Dutch Ministry of Economic Affairs, the University Medical Centre Groningen (UMCG the Netherlands), University Groningen and the Northern Provinces of the Netherlands.

Contributors DD, JB, KdH and ALH contributed to the development of the study design; DD conducted the statistical analyses, wrote the first draft of the paper and acts guarantor of the manuscript. JB, KdH and ALH commented on the manuscript drafts and all authors approved the final version.

Funding This work was supported by the National Institute for Health Research (NIHR) Health Protection Research Unit in Environmental Exposures and Health, a partnership between Public Health England, the Health and Safety Executive and the University of Leicester, under grant number NIHR200901 (to ALH). The views expressed are those of the author(s) and not necessarily those of the NIHR, Public Health England, the Health and Safety Executive or the Department of Health and Social Care.

Competing interests JB reports grants from CIHR, grants from Canadian Respiratory Research Network (CRRN), personal fees from Canadian Thoracic Society, personal fees from CHEST, grants from Foundation of the MUHC, grants from Aerocrine, grants and personal fees from AstraZeneca, grants and personal fees from Boehringer Ingelheim, grants and personal fees from Grifols, grants and personal fees from GlaxoSmithKline, grants and personal fees from Novartis, grants and personal fees from Trudell, all outside the submitted work.

Patient consent for publication Not required.

Ethics approval Lifelines received ethics approval from the Medical Ethics Review Board of the University Medical Centre Groningen (approval letter ref: M07.052740). 
Provenance and peer review Not commissioned; externally peer reviewed.

Data availability statement Data may be obtained from a third party and are not publicly available. Lifelines provides access to data and samples for research on healthy ageing. Information on how to submit a data access application can be found at: https://www.lifelines.nl/researcher/how-to-apply.

Open access This is an open access article distributed in accordance with the Creative Commons Attribution 4.0 Unported (CC BY 4.0) license, which permits others to copy, redistribute, remix, transform and build upon this work for any purpose, provided the original work is properly cited, a link to the licence is given, and indication of whether changes were made. See: https://creativecommons.org/ licenses/by/4.0/.

\section{ORCID iDs}

Jean Bourbeau http://orcid.org/0000-0002-7649-038X

Anna L Hansell http://orcid.org/0000-0001-9904-7447

\section{REFERENCES}

1 Kim V, Criner GJ. Chronic bronchitis and chronic obstructive pulmonary disease. Am J Respir Crit Care Med 2013;187:228-37.

2 Lahousse L, Seys LJM, Joos GF, et al. Epidemiology and impact of chronic bronchitis in chronic obstructive pulmonary disease. Eur Respir J 2017;50:1602470.

3 Vestbo J, Prescott E, Lange P. Association of chronic mucus hypersecretion with FEV1 decline and chronic obstructive pulmonary disease morbidity. Copenhagen City heart Study Group. Am J Respir Crit Care Med 1996;153:1530-5.

$4 \mathrm{Kim}$ V, Han MK, Vance GB, et al. The chronic bronchitic phenotype of COPD: an analysis of the COPDGene study. Chest 2011;140:626-33.

5 Burgel P-R, Nesme-Meyer P, Chanez P, et al. Cough and sputum production are associated with frequent exacerbations and hospitalizations in COPD subjects. Chest 2009; 135:975-82.

6 Seemungal TA, Donaldson GC, Paul EA, et al. Effect of exacerbation on quality of life in patients with chronic obstructive pulmonary disease. Am J Respir Crit Care Med 1998;157:1418-22.

7 de Oca MM, Halbert RJ, Lopez MV, et al. The chronic bronchitis phenotype in subjects with and without COPD: the PLATINO study. Eur Respir I 2012;40:28-36.

8 Mejza F, Gnatiuc L, Buist AS, et al. Prevalence and burden of chronic bronchitis symptoms: results from the BOLD study. Eur Respir J 2017;50:1700621.

9 Allinson JP, Hardy R, Donaldson GC, et al. The presence of chronic mucus hypersecretion across adult life in relation to chronic obstructive pulmonary disease development. Am J Respir Crit Care Med 2016;193:662-72.

10 de Marco R, Accordini S, Cerveri I, et al. Incidence of chronic obstructive pulmonary disease in a cohort of young adults according to the presence of chronic cough and Phlegm. Am J Respir Crit Care Med 2007;175:32-9.

11 Probst-Hensch NM, Curjuric I, Pierre-Olivier B, et al. Longitudinal change of prebronchodilator spirometric obstruction and health outcomes: results from the SAPALDIA cohort. Thorax 2010;65:150-6.

12 Martinez $\mathrm{CH}$, Kim V, Chen $\mathrm{Y}$, et al. The clinical impact of non-obstructive chronic bronchitis in current and former smokers. Respir Med 2014;108:491-9.

13 Thurston GD, Kipen H, Annesi-Maesano I, et al. A joint ERS/ATS policy statement: what constitutes an adverse health effect of air pollution? an analytical framework. Eur Respir J 2017:49:1600419.

14 Guarnieri M, Balmes JR. Outdoor air pollution and asthma. Lancet 2014;383:1581-92.

15 Schikowski T, Mills IC, Anderson HR, et al. Ambient air pollution: a cause of COPD? Eur Respir J 2014;43:250-63.

16 Hoek G, Krishnan RM, Beelen R, et al. Long-Term air pollution exposure and cardiorespiratory mortality: a review. Environ Health 2013;12:43.

17 Medina-Ramón M, Zanobetti A, Schwartz J. The effect of ozone and PM10 on hospital admissions for pneumonia and chronic obstructive pulmonary disease: a national Multicity study. Am J Epidemiol 2006;163:579-88.

18 Faustini A, Stafoggia M, Colais P, et al. Air pollution and multiple acute respiratory outcomes. Eur Respir J 2013:42:304-13.

19 Khreis H, Kelly C, Tate J, et al. Exposure to traffic-related air pollution and risk of development of childhood asthma: a systematic review and meta-analysis. Environ Int 2017;100:1-31.

20 James Gauderman W, McCONNELL ROB, GILLILAND F, et al. Association between air pollution and lung function growth in southern California children. Am J Respir Crit Care Med 2000;162:1383-90.
21 Guo C, Zhang Z, Lau AKH, et al. Effect of long-term exposure to fine particulate matter on lung function decline and risk of chronic obstructive pulmonary disease in Taiwan: a longitudinal, cohort study. Lancet Planet Health 2018;2:e114-25.

22 Doiron D, de Hoogh K, Probst-Hensch N, et al. Air pollution, lung function and COPD: results from the population-based UK Biobank study. Eur Respir J 2019:54:1802140.

23 Cohen AJ, Brauer M, Burnett R, et al. Estimates and 25-year trends of the global burden of disease attributable to ambient air pollution: an analysis of data from the global burden of diseases study 2015. Lancet 2017;389:1907-18.

24 Hooper LG, Young MT, Keller JP, et al. Ambient air pollution and chronic bronchitis in a cohort of U.S. women. Environ Health Perspect 2018;126:027005.

25 Cai Y, Schikowski T, Adam M, et al. Cross-Sectional associations between air pollution and chronic bronchitis: an escape meta-analysis across five cohorts. Thorax 2014:69:1005-14.

26 Scholtens S, Smidt N, Swertz MA, et al. Cohort profile: lifelines, a three-generation cohort study and Biobank. Int J Epidemiol 2015:44:1172-80.

27 Stolk RP, Rosmalen JGM, Postma DS, et al. Universal risk factors for multifactorial diseases. Eur J Epidemiol 2008;23:67-74.

28 Anon. Definition and classification of chronic bronchitis for clinical and epidemiological purposes. A report to the medical Research Council by their Committee on the aetiology of chronic bronchitis. Lancet 1965;1:775-9.

29 Calverley PMA. Cough in chronic obstructive pulmonary disease: is it important and what are the effects of treatment? Cough 2013;9:17.

30 de Hoogh K, Chen J, Gulliver J, et al. Spatial PM2.5, NO2, 03 and bc models for Western Europe - evaluation of spatiotemporal stability. Environ Int 2018;120:81-92.

31 de Hoogh K, Gulliver J, Donkelaar Avan, et al. Development of West-European PM and $\mathrm{NO}_{2}$ land use regression models incorporating satellite-derived and chemical transport modelling data. Environ Res 2016;151:1-10.

32 R Core Team. R: A language and environment for statistical computing.. In: $R$ foundation for statistical computing. Vienna, Austria, 2018.

33 Zemp E, Elsasser S, Schindler C, et al. Long-Term ambient air pollution and respiratory symptoms in adults (SAPALDIA study). The SAPALDIA team. Am I Respir Crit Care Med 1999;159:1257-66.

34 Schikowski T, Adam M, Marcon A, et al. Association of ambient air pollution with the prevalence and incidence of COPD. Eur Respir I 2014;44:614-26.

35 Sunyer J, Jarvis D, Gotschi T, et al. Chronic bronchitis and urban air pollution in an international study. Occup Environ Med 2006;63:836-43.

36 Jenkins CR, Chapman KR, Donohue JF, et al. Improving the Management of COPD in Women. Chest 2017;151:686-96.

37 Langhammer A, Johnsen R, Gulsvik A, et al. Sex differences in lung vulnerability to tobacco smoking. Eur Respir J 2003;21:1017-23.

38 Ben-Zaken Cohen S, Paré PD, Man SFP, et al. The growing burden of chronic obstructive pulmonary disease and lung cancer in women. Am J Respir Crit Care Med 2007; 176:113-20

39 Yunginger JW, Reed CE, O'Connell EJ, et al. A community-based study of the epidemiology of asthma: incidence rates, 1964-1983. Am Rev Respir Dis 1992;146:888-94.

40 Guerra S, Sherrill DL, Venker C, et al. Chronic bronchitis before age 50 years predicts incident airflow limitation and mortality risk. Thorax 2009;64:894-900.

41 Eeftens $\mathrm{M}$, Beelen R, Fischer $\mathrm{P}$, et al. Stability of measured and modelled spatial contrasts in NO(2) over time. Occup Environ Med 2011;68:765-70.

42 Janssen NAH, Hoek G, Simic-Lawson M, et al. Black carbon as an additional indicator of the adverse health effects of airborne particles compared with PM10 and ${ }_{\text {PM2.5. }}$. Environ Health Perspect 2011;119:1691-9.

$43 \mathrm{Kim} \mathrm{V}$, Crapo J, Zhao H, et al. Comparison between an alternative and the classic definition of chronic bronchitis in COPDGene. Ann Am Thorac Soc 2015;12:332-9.

44 Kim V, Zhao H, Boriek AM, et al. Persistent and newly developed chronic bronchitis are associated with worse outcomes in chronic obstructive pulmonary disease. Ann Am Thorac Soc 2016;13:1016-25.

45 Schmidt CO, Kohlmann T. When to use the odds ratio or the relative risk? Int J Public Health 2008;53:165-7.

46 Zhang J, Yu KF. What's the relative risk? A method of correcting the odds ratio in cohort studies of common outcomes. JAMA 1998;280:1690-1.

47 Doiron D, de Hoogh K, Probst-Hensch N, et al. Residential air pollution and associations with wheeze and shortness of breath in adults: a combined analysis of cross-sectional data from two large European cohorts. Environ Health Perspect 2017; 125:097025. 